\title{
CrN Kaplanmış AISI 52100 Çeliğinin Atmosfer ve Vakum ortamlarında Aşınma Davranışının İncelenmesi
}

\author{
Levent KARA* \\ Erzincan Binali Yıldırım Üniversitesi, Makine Mühendisliği Bölümü, Erzincan
}

\begin{abstract}
$\ddot{O} \mathbf{z}$
Bu çalışmada farklı taban malzeme bias gerilimleri uygulanarak üretilen $\mathrm{CrN}$ kaplamalarının morfolojik, yapısal, kimyasal ve aşınma dayanımı özellikleri incelenmiştir. Sanayide yaygın bir şekilde kullanılan AISI 52100 çeliği taban malzeme olarak seçilmiştir. Kaplama yöntemi olarak fiziksel buhar biriktirme yöntemi kullanılmıştır. Kaplamaların morfolojik özellikleri taramalı elektron mikroskobu kullanılarak incelenmiștir. Kaplamaların kristolografik yapıları X ışını difraksiyonu yöntemi kullanılarak analiz edilmiştir. Kaplamaların kimyasal bileşenleri EDS analizi ile incelenmiştir. Kaplamaların aşınma dayanımı özellikleri $5 \times 10^{-3}$ mbar vakum ve normal atmosfer ortamlarında sabit hız, süre ve yük deney parametrelerinde disk üzeri bilye deney düzeneği kullanılarak incelenmiştir. Aş̧nma hacimleri temassız optik profilometre ile ölçülmüştür. Aşınma mekanizmaları aşınma izlerinden alınan SEM ve EDS analizleri ile karakterize edilmiştir. Bu çalışmada kullanılan kaplama parametreleriyle elde edilen $\mathrm{CrN}$ kaplamaların aşınma dayanımlarını belirlemek için yapılan deneylerden elde edilen sonuçlara göre; atmosfer şartlarında $\mathrm{CrN}$ kaplanmış bütün numunelerin, kaplanmamış numunelere göre daha düşük aşınma miktarına sahip olduğu gözlenmiştir. Atmosfer koşullarında en düşük aşınma miktarı, taban malzemelere 200 Volt bias uygulanan numunelerden elde edilirken, vakum ortamında en düşük aşınma miktarı taban malzemelere 100 Volt bias gerilimi uygulanan numunelerden elde edilmiştir. Atmosfer ortamında aşınma mekanizması bütün numunelerde oksidatif ve abrazif olarak gözlemlenirken, vakum ortamında aşınma mekanizması adhezif olarak gözlenmiştir.
\end{abstract}

Anahtar kelimeler: Fiziksel Buhar Kaplama, Vakum, Aşınma, AISI 52100.

\section{Investigation of Wear Behavior of CrN Coated AISI 52100 Steel under Atmospheric and Vacuum Environment}

\begin{abstract}
In this study, it has been investigated morphological, structural, chemical and wear resistance properties of $\mathrm{CrN}$ coatings produced by applying different bias voltages on substrate material. AISI 52100 steel which is widely used in industry was selected as a substrate material. Physical vapor deposition method was used as the deposition method. The morphological properties of the coatings were investigated using scanning electron microscopy. Crystallographic structures of the coatings were analyzed using X-ray diffraction method. The chemical components of the coatings were examined by EDS analysis. The wear resistance properties of the coatings were investigated by using a ball on-disk method at constant speed, duration and load test parameters in $5 \times 10^{-3}$ mbar vacuum and normal atmosphere. Wear volume were measured by contactless optical profilometer. The wear mechanisms are characterized by SEM and EDS analyzes taken from wear traces. From the wear tests, it was observed that all the samples coated with $\mathrm{CrN}$ under atmospheric conditions had a lower amount of wear than the uncoated specimens. The lowest amount of wear in atmospheric conditions was obtained from samples subjected to 200 Volt bias to substrate materials while the lowest amount of wear in vacuum was obtained from samples subjected to 100 Volt bias voltage to substrate materials. The wear mechanism in the atmospheric environment was observed oxidatively and abrasive in all samples, while the wear mechanism in the vacuum environment was mainly adhesive.
\end{abstract}

Keywords: Physical Vapour, Deposition, Vacuum, Wear, AISI 52100.

\footnotetext{
*Sorumlu yazar: lkara@erzincan.edu.tr

Geliş Tarihi: 13.07.2018, Kabul Tarihi: 30.10 .2018
} 


\section{Giriş}

Makine elemanlarında meydana gelen hasarların başında aşınma gelmektedir. Eski çağlardan günümüze kadar birbiriyle eş çalışan yüzeylerde sürtünmeyi azaltmak ve aşınma dayanımını artırmak için çeşitli yöntemler kullanılmıştır. $\mathrm{Bu}$ yöntemlerin başında çalışma yüzeyleri arasına sıvı yağlayıcıların uygulanması gelmektedir. Ancak pek çok uygulamalarda sıv1 yağlayıcıların kullanılması için ek tertibatlara gereksinim duyulması, çevre kirliliğine sebep olması, yüksek sıcaklıklarda yağın yapısının bozulması gibi nedenlerinden dolayı kullanımı istenmektedir. Bunun yanında uzayda çalışan araçlar örneğin; jireskoplar, uydular, aktüatörler, anten sürücüleri, sensör işaretleme mekanizmaları, dişililer, pompalar sanayide kullanılan endüstriyel vakum içeren kaplama cihazlarının vakum odalarındaki hareketli mekanizmaları ve taramalı elektron mikroskobu gibi ileri karakterizasyon cihazlarının çalışabilmeleri için vakum ortamlarında çalıştıklarından dolayı bu cihazların hareketli elemanlarında aşınmayı azaltmak için sıvı yağlayıcılar uçuculuklarından dolayı yağlayıcı olarak kullanılamamaktadır [1],[2]. Bahse konu olan bütün bu uygulamalarda birbiriyle eş çalışan makine elemanlarında sürtünmeyi azaltmak ve aşınma direncini artırmak için malzeme yüzeylerine ince bir film şeklinde çeşitli malzemelerin kaplanması sıvı yağlayıcıların yerine geçebilecek etkili bir yöntem olarak karşımıza çıkmaktadır. Özellikle geçiş metallerinin nitrürlü bileşikleri ile ilgili bu kapsamda pek çok çalışma yapılmıştır. Genel itibariyle kaplamaların özelliklerine pek çok parametre etki etmektedir. Bu parametrelerden bazıları kaplama işleminin gerçekleştirilmiş olduğu ortam basıncı, taban malzemelerin sıcaklığ 1 ve plazmadaki iyonların taban malzemeye yönlendirilmesi için taban malzemelere uygulanan bias gerilimidir. Kaplama işleminin gerçekleştirildiği ortam basıncı arttırıldığında plazma içerisindeki iyonlar arasındaki ortalama serbest yol azalmakta ve bunun neticesinde hedef malzemeden kopartılan atomların taban malzemeye ulaşımı azalmakta buda genel itibariyle kaplama kalınlığını ve sertliğini azaltmaktadır [3]. Taban malzeme sıcaklığının arttırılmasıyla malzemenin kristal yapısının amorf halden kristal hale dönüştüğü ayrıca adezyon dayanımının da arttığı ifade edilmiştir [4]. Bias geriliminin artmasıyla da taban malzemeye yönlenen iyonlar kontrol edilerek yüzeye absorbe olmuş atomların hareketliliği iyileşmekte, fazladan çekirdeklenme bölgeleri elde edilmekte ve böylece daha yoğun bir yapının oluşup kaplamaların sertlik ve aşınma direncinin arttığı rapor edilmiş̧ir [5]. Ancak bias voltajının aşırı miktarda arttırılmasıyla bu sefer taban malzeme yüzeyine kaplanan malzeme tekrar sıçratılarak kaplama kalınlığın azalmasına sebebiyet verebilmektedir [6].

CrN esaslı kaplamalar; sahip oldukları yüksek sertlik, tokluk, aşınma ve korozyon gibi özelliklerinden dolayı pek çok endüstriyel uygulamada dikkat çeken geçiş metallerinin nitrürlü kaplamalarından biridir [7, 8]. CrN esaslı kaplamalar günümüze kadar pek çok kaplama yöntemi ile çeşitli taban malzeme yüzeylerine uygulanmıştır. Yapılan bir çalışmada katotik erozyon/DC manyetik alanda sıçratma tekniğiyle CrN kaplanmış numuneler kaplanmamış AISI H13 ve AISI 316 çeliklerine göre normal atmosfer şartlarında daha iyi aşınma dayanımı gösterdiği ifade edilmiştir [9]. Başka bir çalışmada ise ark iyon kaplama yöntemiyle alüminyum 2024 alaşımı üzerine CrN kaplanmış numunelerin deniz suyu ortamında yapılan aşınma deneylerinde kaplanmamış numunelere göre daha iyi bir aşınma dayanımı gösterdiği rapor edilmiştir [10]. Korozyon direncinin incelendiği diğer bir çalışmada, reaktif DC manyetik alanda sıçratma tekniği ile düşük çalışma basıncı ile üretilmiş CrN kaplamasının daha yüksek korozyon direncine sahip olduğu ifade edilmiştir [11]. Reaktif manyetik alanda sıçratma tekniğinin kullanıldığı ve hedef gücünün CrN kaplamasının özellikleri üzerine etkisinin incelendiği bir çalışmada hedef malzemeye uygulanan gücün artmasıyla kaplamaların sertliklerinin arttığı ifade edilmiştir [12]. Dengesiz manyetik alanda sıçratma tekniği kullanılarak yapılan başka bir çalışmada düşük enerjili iyon bombardımanının sertliği düşürdüğü, yüksek iyon bombardımanında yüksek kalıntı bası gerilmelerini artırdığı, sertliği artırdığı daha yoğun ve pürüzsüz bir kaplama özelliklerinin elde edilmesini sağladığını rapor edilmiştir [13]. Reaktif manyetik alanda sıçratma tekniği kullanılarak yapılan başka bir çalışmada kaplamaların tane boyutunun azalmasının sertliği artırdığı ifade edilmiştir [14]. Reaktif manyetik alanda sıçratma tekniği ile yapılan başka bir çalışmadan düşük $\mathrm{N}_{2} / \mathrm{Ar}$ oranının $\mathrm{Cr}+\mathrm{Cr}_{2} \mathrm{~N}$ şeklinde ikili faz oluşturduğu ve akış oranının arttırılmasıyla $\mathrm{Cr}_{2} \mathrm{~N}$ pikinin güçlendiği ve ayrıca yüksek yoğunluğa ve ince taneli yapıya sahip kaplamaların daha yüksek sertliğe sahip oldukları rapor edilmiştir [15]. Radio frekans manyetik alanda sıçratma tekniği kullanılarak azot gaz akışının etkisinin değerlendirildiği bir çalışmada en yüksek sertliğin \% 12 Azot akışının olduğu kaplamada elde edildiği ifade edilmiştir [16]. Farklı aşınma deneyi parametrelerinin fiziksel buhar biriktirme tekniği kullanılarak elde edilmiş CrN kaplamasına etkilerinin incelendiği bir çalışmada özgül 
aşınma hızının artan yük ve hız ile birlikte azaldığı, sürtünme katsayısının ise artan yük ve kayma hızı ile arttı̆̆ ifade edilmiştir [17].

Yapılan literatür incelemeleri sonucunda CrN kaplamalarıyla ilgili pek çok çalışma yapılmasına rağmen, vakum şartlarında ki aşınma özellikleriyle ilgili yeterince çalışma yapılmadığı gözlemlenmiştir. $\mathrm{Bu}$ çalışmada $\mathrm{CrN}$ kaplamasının vakum ortamında aşınma özellikleri incelenerek literatürde bu boşluğun giderilmesine katkıda bulunulmuştur.

\section{Materyal ve Metot}

\subsection{Kaplama İşlemleri}

$\mathrm{Bu}$ çalışmada fiziksel buhar biriktirme yöntemlerinden biri olan manyetik alanda sıçratma tekniği kullanılarak, farklı taban malzeme bias gerilimleriyle AISI 52100 çeliği üzerine biriktirilen $\mathrm{CrN}$ kaplamalarının normal atmosfer ve vakum ortamlarında sürtünme katsayısı, aşınma miktarı ve aşınma mekanizmaları araştırıldı. Kaplama tekniği olarak manyetik alanda sıçratma tekniğinin seçilmesinin nedeni daha hatasız bir yüzey elde edilmesi, kaplama hızının yüksek olması ve kaplama işleminde pek çok parametrenin kolay bir şekilde kontrol edilebilmesidir. Kaplama cihazının fotoğrafi Şekil 1'de verilmiştir.

Kaplama işlemleri öncesinde taban malzeme olarak seçilen AISI 52100 çelikleri $5 \mathrm{~mm}$ kalınlığında $25 \mathrm{~mm}$ çapında disk şeklinde hazırlandı. Homojen bir yüzey elde edebilmek ve muhtemel kirleri yüzeyden uzaklaştırmak için bütün numuneler sırasıyla kaba zımparalama, ince zımparalama ve parlatma işlemlerine tabi tutuldu. Bu işlemlerin ardından numuneler etil alkol havuzunda 15 dakika ultrasonik temizleme işlemine tabi tutuldu. Daha sonra numuneler hava ile kurutuldu.

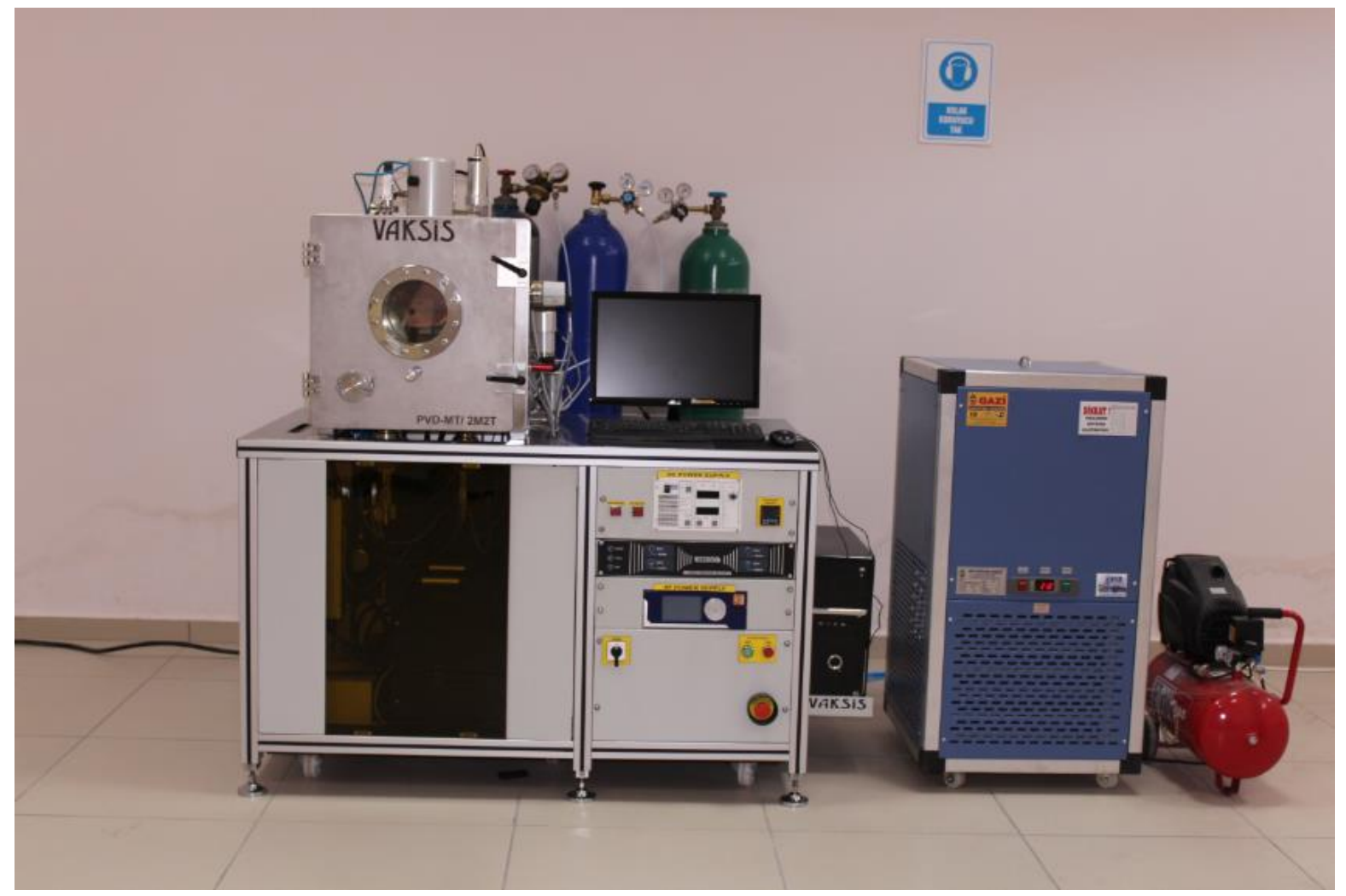

Şekil 1. Manyetik alanda sıçratma sisteminin fotoğrafi

Kaplama cihazında bir adet RF (Radio Frequency) ve bir adet DC (Direct Current) güç kaynağı bağlı iki magnetron bulunmaktadır. Kaplama işlemlerinde $\mathrm{Cr}$ hedef malzemesi DC güç kaynağına bağlı magnetrona takılmıştır. Kaplama işlemleri öncesinde numuneler 30 dakika yüksek saflıktaki Argon gazı ile iyon temizleme işlemine tabi tutulmuştur. Kaplama işlemi $450^{\circ} \mathrm{C}$ 'de yapılmıştır. Kaplama parametreleri Tablo 1'de verilmiştir. 
Taban malzeme yüzeylerine dış kaplama tabakasının adezyonunu artırmak ve kaplama ile taban malzeme arasındaki gerilmeleri azaltmak için 10 dakika $\mathrm{Cr}$ ara tabakası kaplanmıştır. $\mathrm{CrN}$ tabakası ise 2 saat 50 dakika kaplanmıştır.

Tablo 1. Kaplama işlemleri için parametreler

\begin{tabular}{|c|c|c|c|c|}
\hline & $\begin{array}{c}\text { Cr Hedef Gücü } \\
\text { (Watt) }\end{array}$ & $\begin{array}{c}\text { Çalışma Basıncı } \\
\text { (mtorr) }\end{array}$ & $\begin{array}{c}\mathbf{N}_{2} \text { Akıs Hızı } \\
\text { (sccm) }\end{array}$ & Bias voltaj (V) \\
\hline CrN300 & 100 & 10 & 10 & 300 \\
\hline CrN200 & 100 & 10 & 10 & 200 \\
\hline CrN100 & 100 & 10 & 10 & 100 \\
\hline
\end{tabular}

\subsection{Kaplamaların analiz işlemleri}

Kaplamaların yüzey morfolojileri taramalı elektron mikroskobu ile yapılmıştır. Kimyasal analizleri EDS (Energy Dispersive Spectroscopy) ile yapılmıştır. Kristolografik yapıları XRD (X Ray Diffraction) cihazı ile belirlendi. Kaplamaların normal atmosfer ve $5 \times 10^{-3} \mathrm{mbar}$ vakum ortamlarındaki aşınma özellikleri disk üzeri bilye deney tekniğiyle belirlendi. Aşınma deney düzeneğinin fotoğrafı Şekil 2'de verilmiştir.

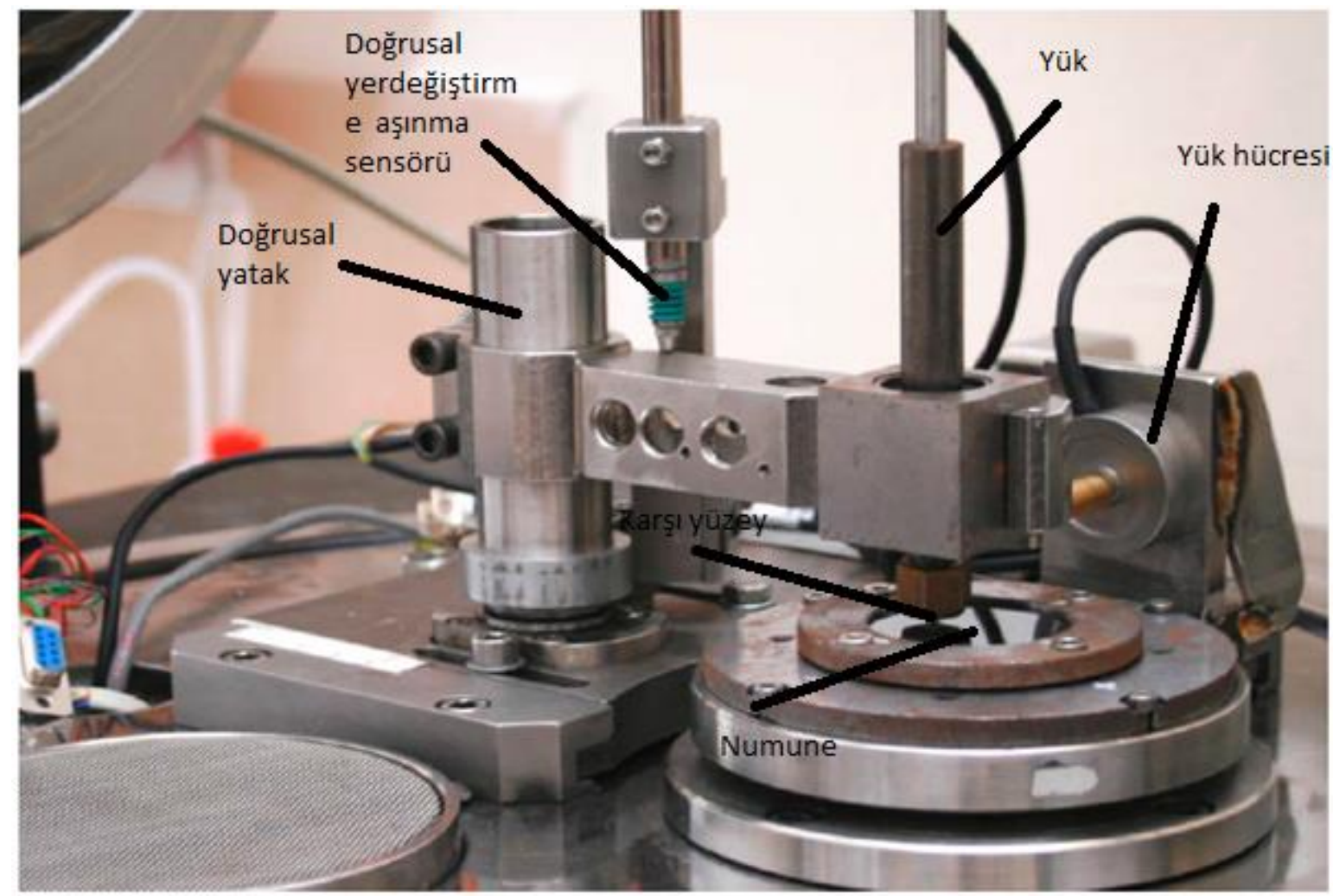

Şekil 2. Disk üzeri bilye aşınma düzeneği fotoğrafi

Aşınma deneylerinde kullanılan parametreler daha önceden yapılan laboratuvar deneyleri ve literatürdeki çalışmalar dikkate alınarak normal yük $2 \mathrm{~N}$, çevresel hız $60 \mathrm{~mm} / \mathrm{sn}$ ve deney süresi 7 dakika (1600 çevrim ) olarak belirlenmiştir. Aşınma deneylerinde karşı yüzey olarak $\mathrm{Si}_{3} \mathrm{~N}_{4}$ bilyeler kullanıldı. Aşınma hacimleri temassız optik profilometre ile ölçüldü. Aşınma yüzeyleri taramalı elektron mikroskobu ve EDS ile incelendi. 


\section{Bulgular ve Tartışma}

\subsection{Morfolojik İncelemeler}

Kaplamaların yüzey morfolojileri taramalı elektron cihazı ile gözlemlendi. Elde edilen yüzey SEM fotoğrafları Şekil 3'de verilmiştir.

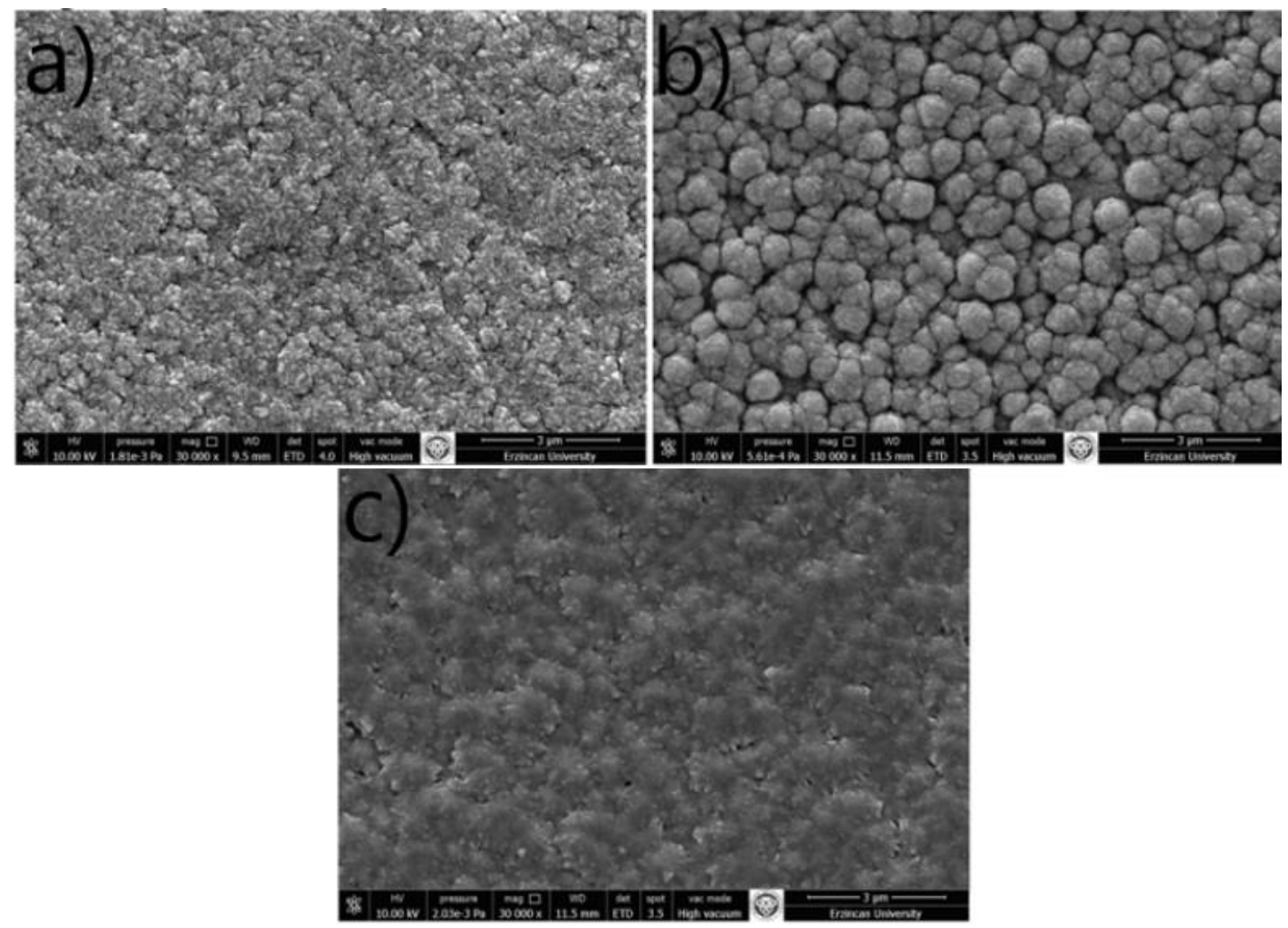

Şekil 3. Kaplamaların yüzey SEM fotoğrafları; a) CrN100, b) CrN200 ve c) CrN300

Şekil 3'den görüldüğü üzere taban malzemelere farklı biasın geriliminin uygulanması kaplamaların yüzey morfolojilerini önemli oranda değiştirmiştir. Taban malzemelere $100 \mathrm{~V}$ bias geriliminin uygulandığı CrN100 numunesinde gözenekli bir yapı elde edilmiştir. Bu yapının Movchan ve Demchishin ve daha sonra Thornton tarafindan geliştirilen Zone 1 yapısı görünümüne benzediği düşünülmektedir [18]. Bu durumun, kaplama prosesi esnasında yüzeye ulaşan absorbe olmuş atomların çok düşük hareketliliğe sahip olmasıyla ilgili olduğu düşünülmektedir [19]. Bias voltajının 200 V'a artırıldığ 1 CrN200 numunesinde ise artan çekirdeklenme ile taneli yapıya sahip bir morfoloji elde edilmiştir. Elde edilen bu yapının artan bias voltajı ile absorbe olmuş atomların hareketliliğinin artmasından kaynaklanabileceği düşünülmektedir [19]. Bu seviyedeki bias voltajıyla absorbe olmuş atomlar birbirleriyle difüzyon olarak kristal adalar gibi bir yapı oluşturmuşlardır. Burada absorbe atomlar sadece bir adaya difüzyon olabilmektedir. Bu nedenle CrN200 kaplamasındaki taneler ya da adalar birbirleriyle kaynaşamadığından dolayı yapı düz kolon şeklinde oluşmuştur (Şekil 4) [19]. Bias voltajının 300 V'a artırıldığ $\mathrm{CrN300}$ numunesinde ise bulk difüzyonun arttığı, yoğun ve sık1 paketlenmiş zone $\mathrm{T}$ şekline benzeyen bir yapı elde edilmiştir [18]. Bu sonuçları kesitlerden alınan SEM fotoğrafları da doğrulamaktadır (Şekil 4).

Kaplama kesitlerinden yapılan ölçümlerden CrN100, CrN200 ve CrN300 numunelerinin kalınlıkları sırasıyla $868 \mathrm{~nm}, 979 \mathrm{~nm}$ ve $750 \mathrm{~nm}$ olarak ölçülmüştür. Burada taban malzemelere uygulanan bias geriliminin $100 \mathrm{~V}$ değerinden $200 \mathrm{~V}$ değerine artırılmasıyla kaplama kalınlığının da $868 \mathrm{~nm}$ değerinden $979 \mathrm{~nm}$ değerine arttığı tespit edilmiştir. Bu durum artan bias voltajıyla plazmadan taban malzemeye daha fazla iyonun ulaşmasıyla ilişsili olduğu düşünülmektedir. Bias geriliminin $300 \mathrm{~V}$ değerine artırılmasıyla bu sefer kaplama kalınlığının $750 \mathrm{~nm}$ değerine düştüğü görülmektedir. $\mathrm{Bu}$ durumun ise bahse konu olan bias gerilimi değerinin plazmada bulunan iyonların oldukça yüksek enerjili 
olarak taban malzeme üzerine yönlendirerek, daha önce biriken kaplamayı tekrar yerinden geriye sıçratmasıyla (re-sputtering) ilgili olduğu düşünülmektedir [20-22].
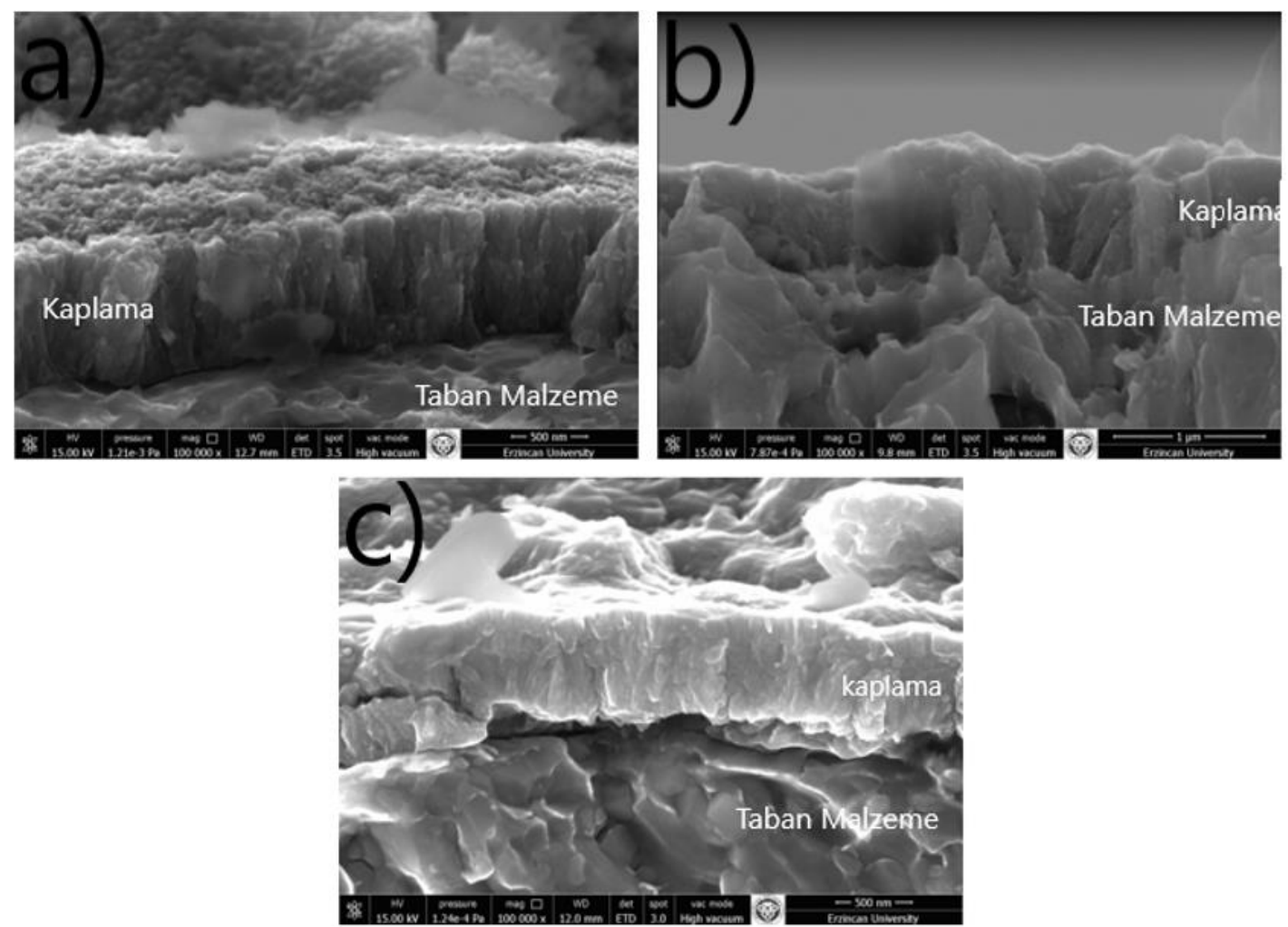

Şekil 4. Kaplamaların kesitlerinin SEM fotoğrafları; a) CrN100, b) CrN200 ve c) CrN300

\subsection{XRD analizleri}

Taban malzemelere uygulanan farklı bias gerilimi sonucunda elde edilen kaplamaların XRD analiz sonuçları Şekil 5'te verilmiştir.

Şekil 5'ten görüldüğü üzere CrN100 numunesinde $38^{\circ}$ açısında $\mathrm{CrN}(111)$ ve $43^{\circ}$ açısında $\mathrm{CrN}$ (200) pikleri elde edilmiştir [15]. Taban malzemelere uygulanan biasın 100V'tan 200V'a çıkartıldığ1 CrN200 numunesinde bu piklere ek olarak sıçratma atomlarının enerjilerinin artmasıyla $56-57^{\circ}$ $\mathrm{Cr}_{2} \mathrm{~N}(112)$ piki gözlenmiştir. Ancak bu pikin şiddeti bias voltajının $300 \mathrm{~V}$ değerine çıkartıldığ $1 \mathrm{CrN} 300$ numunesinde taneler arası difüzyonun artmasıyla azalmıştır. Taban malzemelere uygulanan bias voltajının $300 \mathrm{~V}$ olduğu $\mathrm{CrN} 300$ numunesinde ise sadece $\mathrm{CrN}$ (200) piki elde edilmiş olup, şiddetinin ise diğer numunelere göre önemli oranda azaldığı gözlenmiştir. Bir kaplamanın kristolografik gelişimi birikme esnasında termodinamik ve kinetik mekanizmalarla ilişkili olmaktadır. Termodinamik şartlar altında CrN kaplamasının (100) düzleminde büyümesi beklenmektedir. Bunun nedeni (100) düzleminin (110) ve (111) düzlemlerinden daha düşük yüzey enerjisine sahip olmasıdır [23]. Eğer kinetik mekanizmalar baskın ise bu sefer birçok çalışmada görüldüğü üzere (111) düzlemi üzerinde büyüme olmaktadır. Bu çalışmada da taban malzemelere uygulanan bias gerilimi neticesinde $\mathrm{CrN}$ (111) piki CrN100 ve CrN200 numunelerinde gözlenmiştir. Ancak CrN300 numunesinde taban malzemelere uygulanan bias voltajının $300 \mathrm{~V}$ değerine çıkartılmasıyla enerjisi aşırı bir şekilde artan sıçratma iyonları büyüyen kaplamada tekrar geriye sıçratma, tavlama ve absorbe olmuş atomların (adatom) difüzyonunun kolaylaşmasıyla $\mathrm{CrN}(111)$ pikinin şiddetinin azalarak kaplamanın yarı amorf halde büyümesine neden olmuştur. Aynı mekanizma CrN(200) pikinde de etkili olduğu düşünülmektedir. 

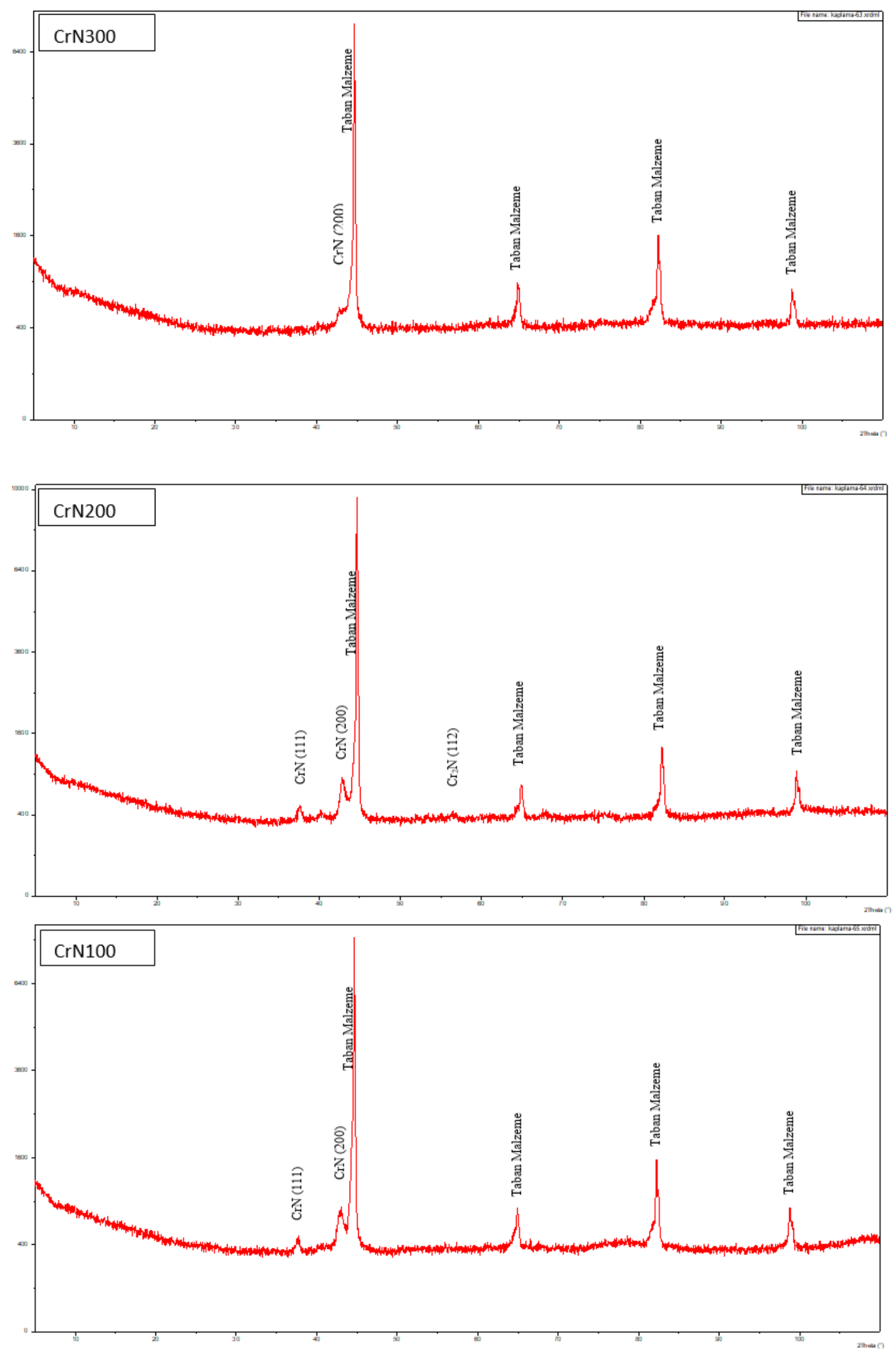

Şekil 5. CrN kaplı numunelerin ve taban malzemenin XRD pikleri 


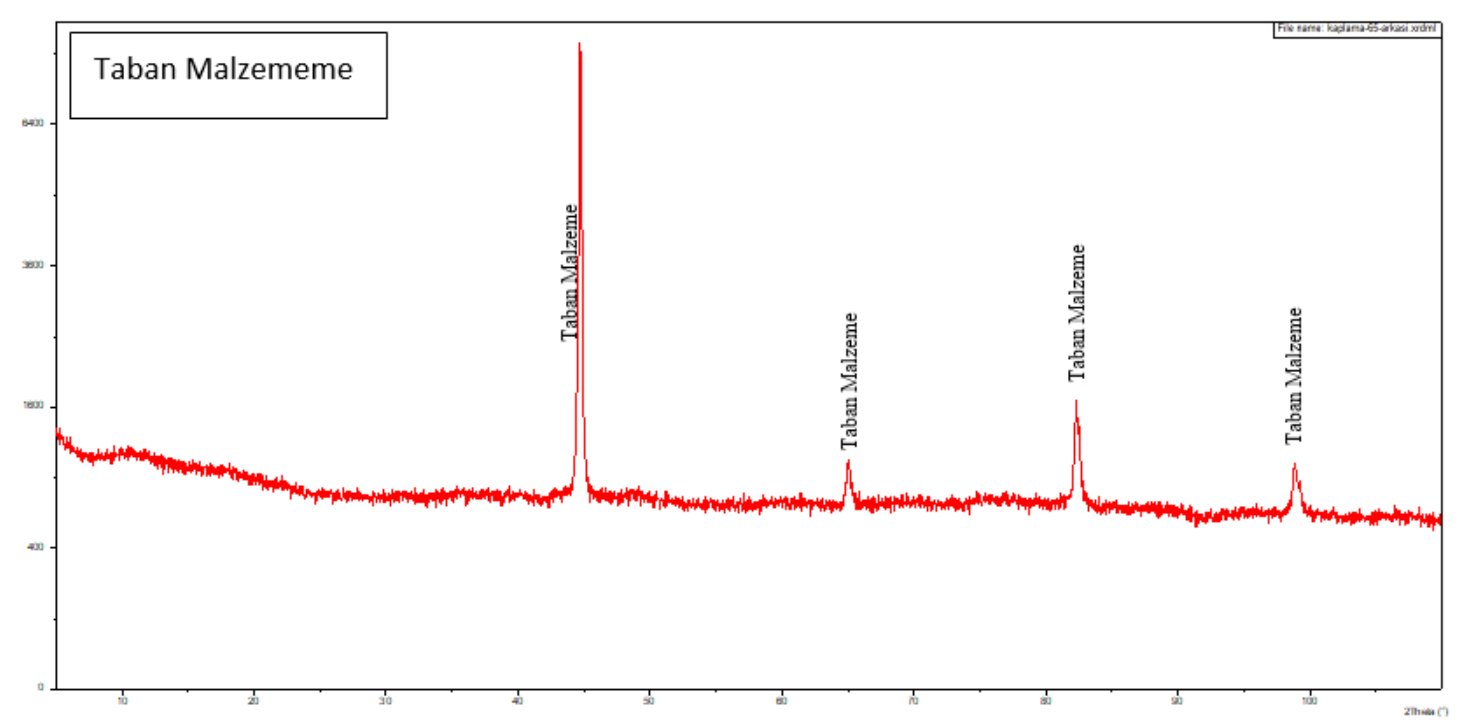

Şekil 5 (devamı). CrN kaplı numunelerin ve taban malzemenin XRD pikleri

\subsection{Kimyasal Bileșim Analizleri}

Tablo 2'ye bakıldığında Azot miktarının $100 \mathrm{~V}$ bias gerilimi uygulanan CrN100 numunesinde atomik olarak \%15,41 olduğu ve bias voltajının 200 V'a çıkartılmasıyla beraber az miktarda arttığı görülmektedir. Bu durumun artan bias voltajı ile birlikte plazma içerisinde azot ve krom atomlarının yoğunluklarının artması ve hızlandırılmış azot atomlarının kaplama tabakası içerisine $\mathrm{CrN}$ bileşiğinden hariç olarak ara yer atomu olarak girmesiyle ilişkili olacağı düşünülmektedir. Bias voltajının 300 V'a arttırıldığı CrN300 numunesinde ise azot miktarının aşırı şekilde azalarak \% 9 olduğu görülmektedir. $\mathrm{Bu}$ durumun ise taban malzemelere uygulanan yüksek bias gerilimi neticesinde enerjisi artmış argon atomlarının krom elementine göre kütlesi düşük olan azot atomlarını geriye sıçratarak (resputtering) kaplamadan uzaklaştırması neticesinde oluştuğu düşünülmektedir.

Tablo 2. AISI 52100 çeliğine kaplanmış numunelerin kimyasal bileşim sonuçları (\% atom)

\begin{tabular}{|l|l|l|l|}
\hline & $\mathrm{N}$ & $\mathrm{Cr}$ & $\mathrm{O}$ \\
\hline CrN300 & 9 & 81 & 9,85 \\
\hline CrN200 & 18,69 & 70,36 & 10,95 \\
\hline CrN100 & 15,41 & 73,8 & 10,79 \\
\hline
\end{tabular}

\subsection{Aşınma Deneyleri Analizleri}

Kaplamaların aşınma deneylerinden elde edilen sürtünme katsayısı eğrileri Şekil 6'da verilmiştir. Şekil 6'dan kaplamaların sürtünme katsayısı eğrilerine bakıldığında stabil bir davranış gösterdiği görülmektedir. Kaplamaların ortalama sürtünme katsayıları Tablo 3 'te verilmiştir. Tablo 3'den genel itibariyle kaplanmıs numunelerin sürtünme katsayıları aralarında önemli miktarda fark bulunmamakla birlikte normal atmosfer koşullarında yapılan deneylerde taban malzemeye göre daha yüksek sürtünme katsayılarına sahip oldukları görülmektedir.

Vakum ortamında yapılan deneylerden elde edilen sürtünme katsayısı eğrileri Şekil 7'de verilmiştir. Vakum ortamında yapılan deneylerde en düşük sürtünme katsayısı CrN100 numunesinden elde edilmiştir. Aynı şartlarda deney tekrarlandığında benzer sonuçlar elde edilmiştir. CrN100 numunesinde düşük sürtünme katsayısı, kaplama ile aşındırıcı bilye arasında oluşan yağlayıcı bir tabaka ile ilgili olduğu düşünülmektedir.

Vakum şartlarında yapılan deneylerden elde edilen sürtünme katsayısı değerleri atmosfer şartlarında yapılan deneylerden elde edilen sürtünme katsayısı değerlerinden daha düşük olduğu görülmüş̧ür (Tablo 3). Benzer sonuç literatürde yapılan çalışmalarda da elde edilmiştir [24-26]. Birbiriyle eş çalışan yüzeylerde yumuşak olan taraftan sert olan tarafa malzeme transferi olmaktadır. $\mathrm{Bu}$ nedenle belirli bir süre sonunda temas eden yüzeylerin karakteri değişmektedir. Bu çalışmada vakum 
ortamında elde edilen sürtünme katsayısının atmosfer ortamında yapılan deneylerden elde edilen sürtünme katsayısından düşük olmasının nedeni bu durumla ilgili olduğu düşünülmektedir. Vakum ortamında deney başlangıcında $\mathrm{CrN}$ kaplamasıyla aşındırıcı bilye $\mathrm{Si}_{3} \mathrm{~N}_{4}$ arasında olan sürtünme, karşı yüzey üzerine $\mathrm{CrN}$ kaplamasının transfer olmasıyla artık belirli oranda $\mathrm{CrN}$ üzeri $\mathrm{CrN}$ sürtünmesine dönüşmüştür. Atmosfer ortamında ise havada bulunan oksijen sebebiyle karşı yüzeye transfer olan tabaka, Tablo 4'te verilen EDS analizlerinden de görüldüğ̈ gibi oksit (Cr-N-O) karakterlidir. Dolayısıyla atmosfer ortamında başlangıçta $\mathrm{Si}_{3} \mathrm{~N}_{4}$ ile $\mathrm{CrN}$ arasında olan sürtünme zaman geçtikçe oksit karakterli olan transfer tabakası ile $\mathrm{CrN}$ arasında meydana gelen sürtünme haline dönüşmüştür. Sert bir yapıya sahip olduğu düşünülen oksit transfer tabakası da atmosfer ortamında sürtünme katsayısını artırmıştır.

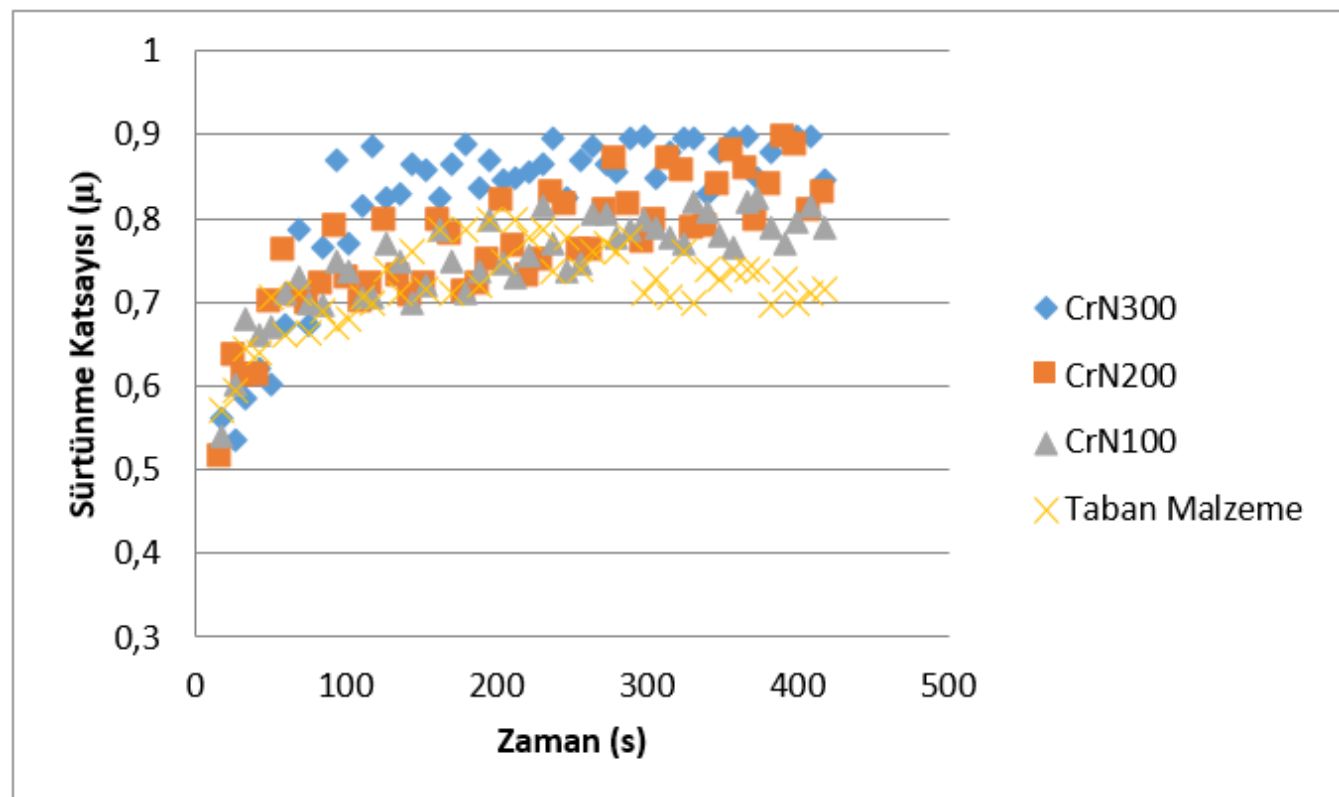

Şekil 6. Atmosfer ortamında yapılan deneylerden elde edilen Sürtünme katsayısı grafiği

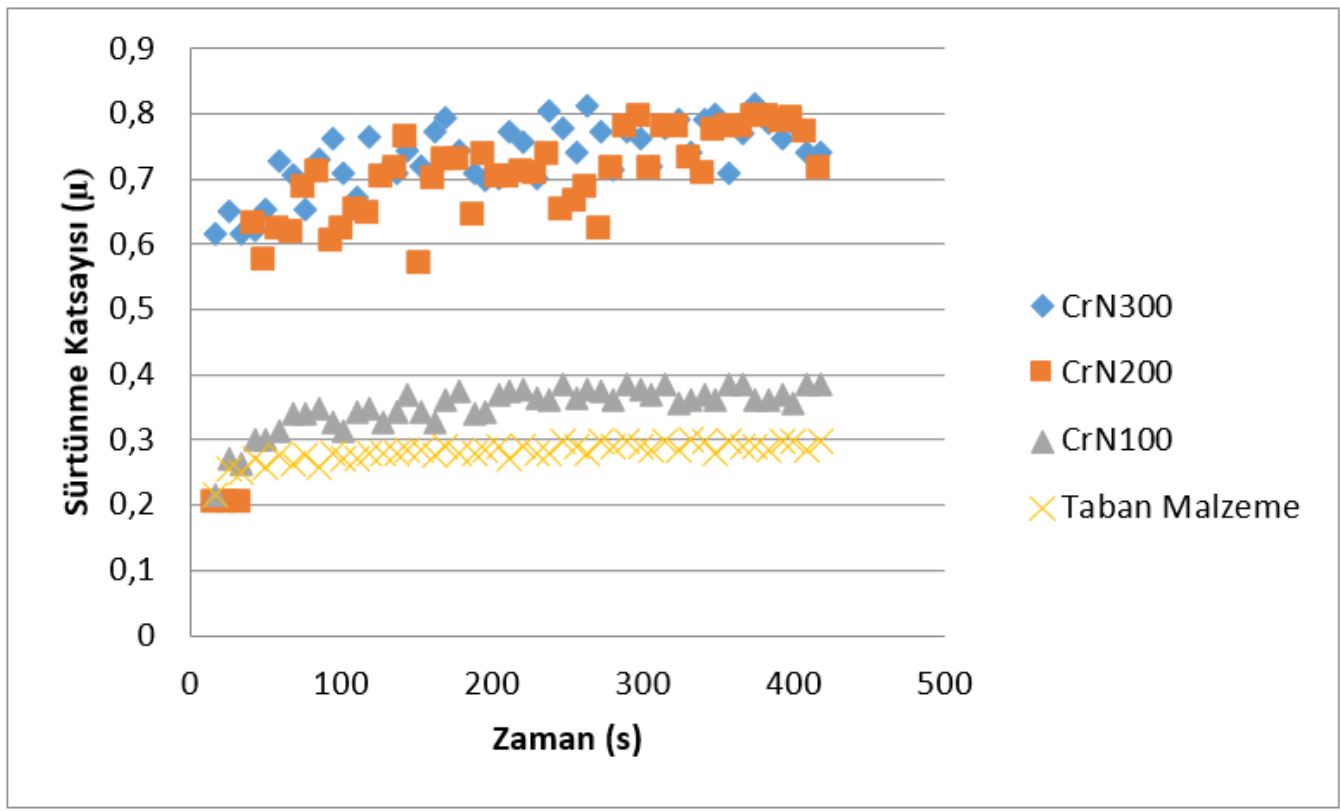

Şekil 7. Vakum ortamında yapılan deneylerden elde edilen sürtünme katsayısı eğrileri

Kaplamaların atmosfer şartlarında ve vakum şartlarında yapılan aşınma deneylerinden elde edilen aşınma miktarları sonuçları Tablo 3'te ve grafikleri Şekil 8'de verilmiştir. 
Tablo 3. Aşınma deneyleri sonuçları

\begin{tabular}{|l|c|c|c|c|}
\hline \multirow{2}{*}{} & \multicolumn{2}{|c|}{$\begin{array}{c}\text { Ortalama } \\
\text { Sürtünme Katsayısı }\end{array}$} & $\begin{array}{c}\text { Aşınma Oranı } \\
\text { Atm } \\
\mathbf{m m}^{\mathbf{3}} /(\mathbf{N m})\end{array}$ & $\begin{array}{c}\text { Aşınma Oranı } \\
\text { Vakum } \\
\mathbf{m m}^{\mathbf{3}} /(\mathbf{N m})\end{array}$ \\
\cline { 2 - 3 } & $\mathbf{A t m}$ & Vakum & $3,59682 \mathrm{E}-05$ & 0,000209 \\
\hline CrN300 & 0,86 & 0,75 & $4,53462 \mathrm{E}-06$ & 0,000189 \\
\hline CrN200 & 0,79 & 0,71 & $2,20025 \mathrm{E}-05$ & $5,46 \mathrm{E}-06$ \\
\hline Taban malzeme & 0,76 & 0,36 & $7,74881 \mathrm{E}-05$ & $3,17 \mathrm{E}-06$ \\
\hline
\end{tabular}

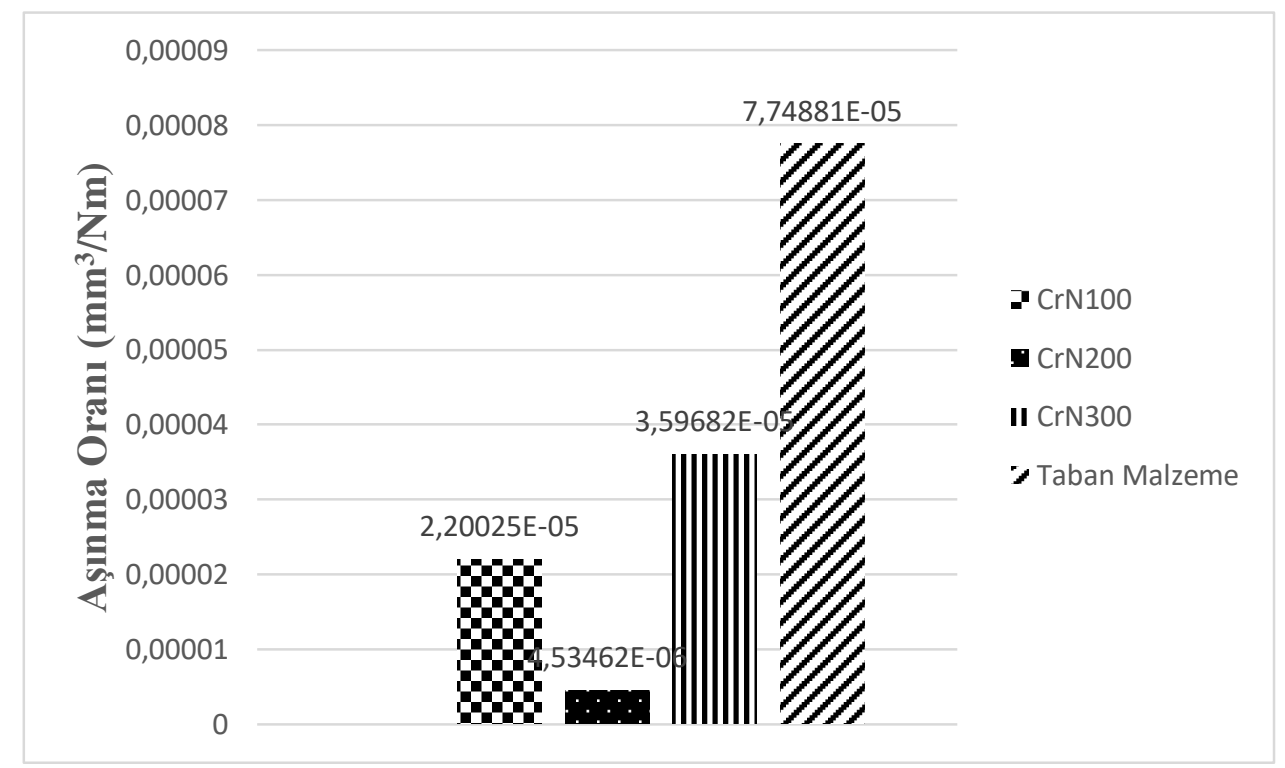

Şekil 8. Atmosfer şartlarında yapılan deneylerden elde edilen aşınma miktarı grafikleri.

Şekil 8'den görüldügü üzere normal atmosfer şartlarında kaplanmış numunelerin tamamı kaplanmamış numuneden daha yüksek aşınma dayanımı göstermiştir. Kaplanmış numunelerin aşınma dayanımı sonuçları kendi içerisinde değerlendirildiğinde en düşük aşınma miktarı $\mathrm{CrN} 200$ numunesinde elde edilirken, en yüksek aşınma miktarı CrN300 numunesinde elde edildiği görülmektedir (Tablo 3). Taban malzemelere uygulanan bias geriliminin $100 \mathrm{~V}$ değerinden $200 \mathrm{~V}$ değerine çıkartılmasıyla aşınma miktarı önemli derecede azalmıştır. Bu durumun CrN200 numunesinin sahip olduğu daha yükssek azot miktarıyla ilişkili olduğu düşünülmektedir (Tablo 2).

Vakum ortamında yapılan aşınma deneylerinden elde edilen aşınma miktarları Tablo 3'te ve grafikleri Şekil 9'da verilmiştir. Şekil 9'dan görüldüğü üzere kaplanmış numunelerin aşınma miktarları kaplanmamış numuneden daha yüksek çıkmıştır. Kaplanmış numuneler kendi içerisinde değerlendirildiğinde en düşük aşınma miktarı CrN100 numunesinden elde edilirken, en yüksek aşınma miktarı CrN300 numunesinden elde edildiği görülmüştür.

Genel itibariyle atmosfer şartlarında vakum şartlarına göre daha düşük aşınma miktarının elde edildiği gözlenmiştir. Bu durumun atmosfer şartlarında kaplama yüzeylerinde yağlayıcı etki yaptığı düşünülen $\mathrm{Cr}-\mathrm{O}$ oksit filmi ile ilgili olduğu düşülmektedir. Hem vakum ortamında hem de atmosfer ortamında yapılan aşınma deneylerinin aşınma yollarından alınan EDS analizlerinde görülen oksijen elementindeki fark bu sonucu doğrulamaktadır (Tablo 4, Tablo 5).

CrN kaplanmış numunelerin aşınma mekanizmaları SEM fotoğrafları ve aşınma izlerinden yapılan EDS ölçümleri ile analiz edilmiştir. Atmosfer ortamında yapılan aşınma deneylerinde elde edilen aşınma izi fotoğrafları Şekil 10'da, EDS analizleri de Tablo 4'te verilmiştir. 


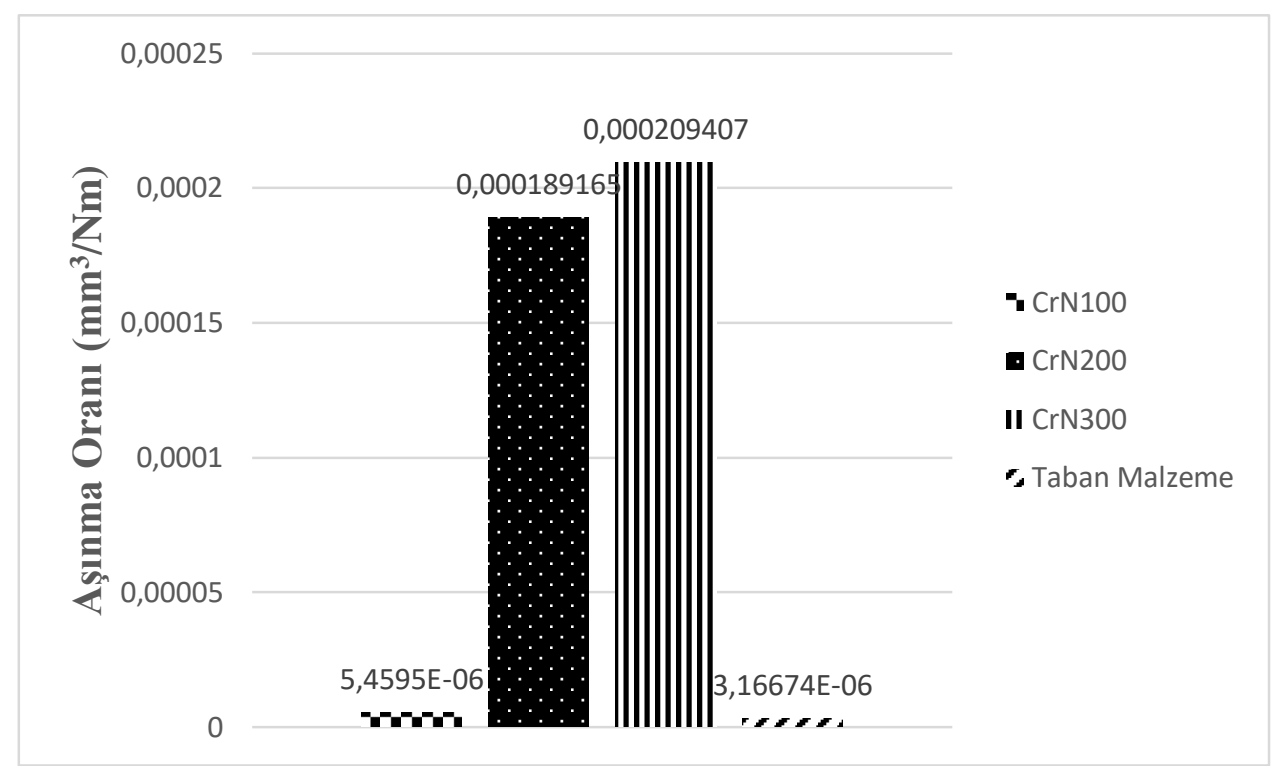

Şekil 9. Vakum ortamında yapılan deneylerden elde edilen aşınma miktarı grafikleri

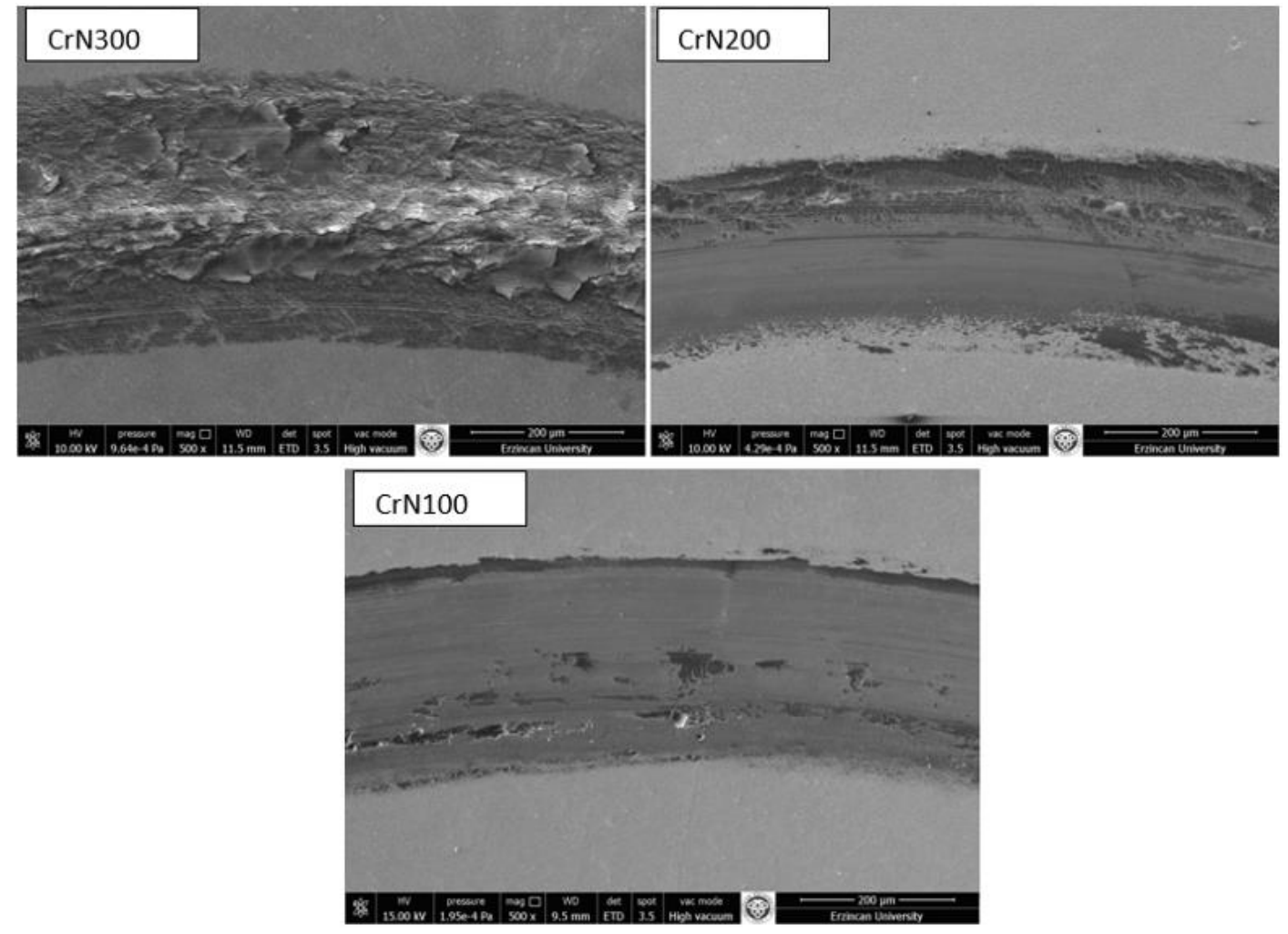

Şekil 10. Atmosfer ortamında yapılan deneylerden elde edilen aşınma yüzeyi SEM fotoğrafları

Şekil 10'da görüldüğü gibi CrN300 kaplamasında oksitadif, abrazif ve parçalı şekilde yüzeyden kalkmanın etkin olduğu görülmektedir. Oksitadif aşınma karakterini, aşınma izi içerisinden alınan EDS analizi sonuçları da doğrulanmaktadır (Tablo 4). CrN200 kaplamasında ise ince çizikler halinde bir aşınma yolu gözlenmiştir. 
Tablo 4. Atmosfer şartlarında yapılan aşınma deneylerinde aşınma izi içerisinden yapılan EDS analizi sonuçları

\begin{tabular}{|l|c|c|c|c|c|c|c|}
\hline & $\mathbf{C}$ & $\mathbf{N}$ & $\mathbf{O}$ & $\mathbf{S i}$ & $\mathbf{V}$ & $\mathbf{C r}$ & $\mathbf{F e}$ \\
\hline CrN300 & 7.89 & 5.33 & 48.91 & 4.03 & 0.27 & 7.16 & 26.4 \\
\hline CrN200 & 9.2 & 18.15 & 18.91 & 0.61 & 0.25 & 33.98 & 18.9 \\
\hline CrN100 & 10.11 & 15.7 & 15.05 & 0.24 & 0.33 & 38.34 & 20.23 \\
\hline
\end{tabular}

Vakum ortamında yapılan aşınma deneylerinden elde edilen aşınma yüzeyi SEM fotoğrafları Şekil 11'de ve EDS analizleri Tablo 5'te verilmiştir.
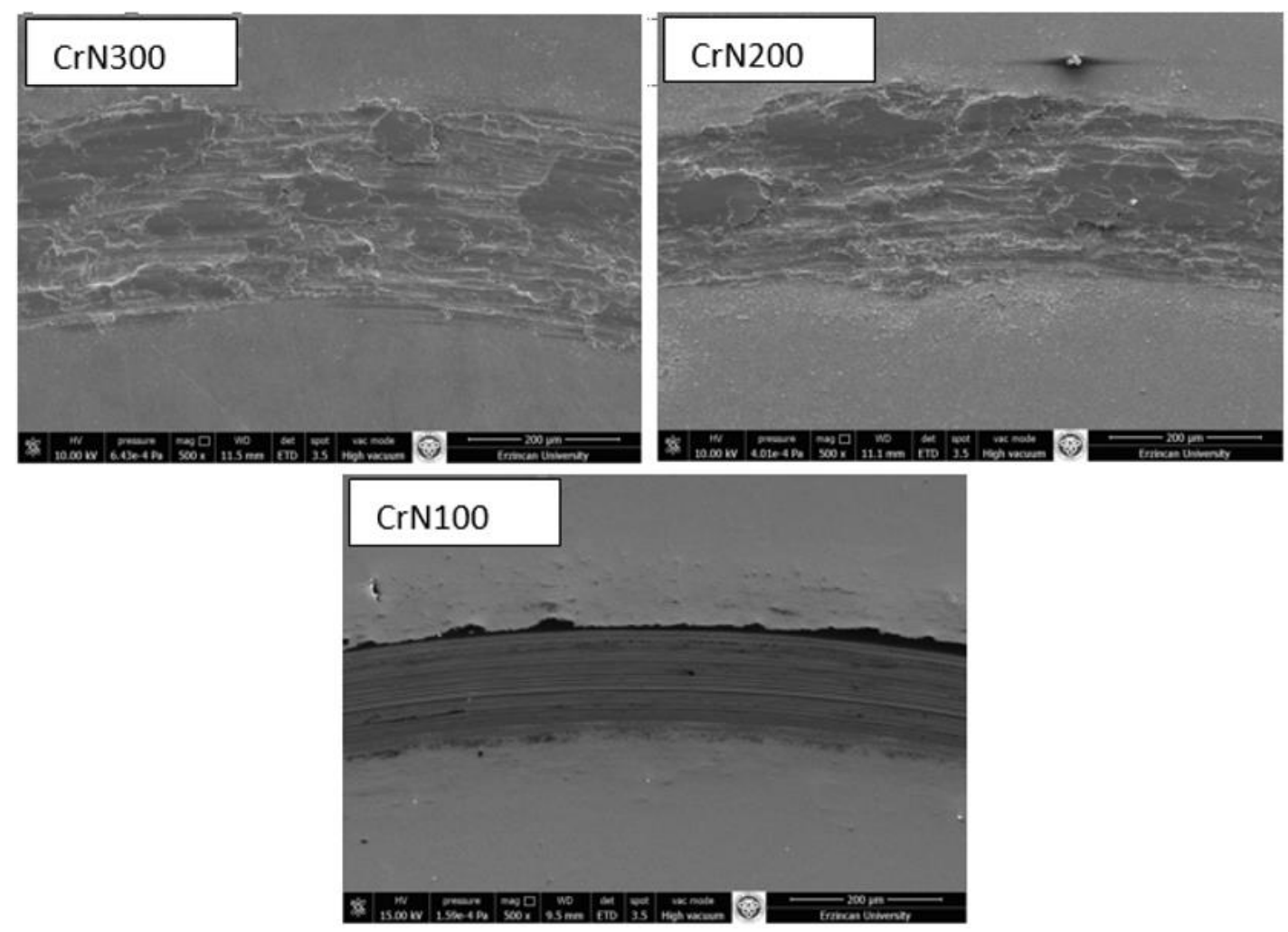

Şekil 11. Vakum ortamında yapılan aşınma deneylerinden elde edilen aşınma izi fotoğrafları

Şekil 11'den görüldüğü üzere vakum ortamında yapılan aşınma deneylerinde CrN300 ve CrN200 kaplamaları taban malzeme yüzeyinden büyük ölçüde kalkmıştır. CrN100 kaplaması ise çok az aşınmıştır. Tablo 5'de vakumda yapılan aşınma deneylerinden aşınma izi içerisinden alınan EDS analizi sonuçlarına bakıldığında CrN300 ve CrN200 numunelerinin çok az bir oksidasyona uğradığı ve CrN100 numunesinin ise daha fazla oksidasyona uğradığı görülmektedir. Buradaki oksijenin kaplama odası içerisinde kalıntı oksijenden kaynaklandığı düşünülmektedir. CrN100'de oluşan bu oksit tabakanın vakum şartlarında yağlayıcı etkiye neden olduğu düşünülmektedir. CrN200 ve CrN300 numunelerine daha fazla bias gerilimi uygulandığından bu numunelerde CrN100 numunesine göre daha fazla arttık gerilme oluştuğu ve bu artık gerilmeler kaplamaların tokluğunu düşürerek kırılgan bir yapıya sahip olmalarını sağladığı düşünülmektedir.

Tablo 5. Vakum ortamında yapılan aşınma deneylerinde aşınma izi içerisinden yapılan EDS analizi sonuçları

\begin{tabular}{|l|c|c|c|c|c|c|c|}
\hline & $\mathbf{C}$ & $\mathbf{N}$ & $\mathbf{O}$ & $\mathbf{S i}$ & $\mathbf{V}$ & $\mathbf{C r}$ & $\mathbf{F e}$ \\
\hline CrN300 & 13.95 & 4.21 & 3.02 & 0.63 & 0.67 & 7.81 & 69.71 \\
\hline CrN200 & 15.73 & 5.18 & 4.85 & 0.64 & 0.69 & 12.24 & 60.66 \\
\hline CrN100 & 10.95 & 16.36 & 12.26 & 0 & 0.38 & 39.06 & 21 \\
\hline
\end{tabular}




\section{Sonuç ve Öneriler}

Bu çalışmada reaktif manyetik alanda sıçratma yöntemiyle AISI 52100 çeliği taban malzemesi üzerine değişik taban malzeme bias gerilimiyle CrN kaplamalar kaplanmıştır. Yapılan deneyler sonucunda aşağıdaki sonuçlar elde edilmiştir.

Taban malzemelere uygulanan bias geriliminin, kaplamaların morfolojik yapılarına önemli oranlarda etkimektedir. $100 \mathrm{~V}$ bias gerilimi uygulandığında boşluklu bir yapı, $200 \mathrm{~V}$ bias gerilimi uygulandığında taneli bir yapı ve $300 \mathrm{~V}$ bias uygulandığında yoğun bir yapı elde edilir.

Taban malzemelere bias gerilimi uygulanmasıyla kaplamaların kristolografik yapıları değişir. $100 \mathrm{~V}$ bias gerilimi uygulandığında $\mathrm{CrN}(111)$ ve $\mathrm{CrN}(200)$ pikleri elde edilrken, $200 \mathrm{~V}$ bias gerilimi uygulandığında bu piklere ek olarak $\mathrm{Cr}_{2} \mathrm{~N}(110)$ piki elde edilmiştir. Bias gerilimi $300 \mathrm{~V}$ değerine çıkartıldığında piklerin şiddeti zayıflamıştır. Kaplama yarı amorf hale gelmiştir.

CrN kaplamalarının normal atmosfer ortamındaki aşınma dayanımı, vakum ortamındaki aşınma dayanımından daha yüksektir.

Atmosfer ortamında en düşük aşınma miktarı taban malzemelere 200 Volt bias geriliminin uygulandığı numunelerden elde edilmiştir.

Atmosfer ortamında aşınma mekanizması abrazif ve oksitadifken, vakum ortamında adezif aşınma mekanizması daha etkindir.

\section{Kaynaklar}

[1] Voevodin A.A., Zabinski J.S. 2015. Nanocomposite and nanostructured tribological materials for space applications, Composites Science and Technology, 65 (5): 741-748.

[2] Gao X., Fu Y., Jiang D., Wang D., Yang J., Weng L., Hu M., Sun J. 2018. Structural, Mechanical, and Tribological Properties of WS2-Al Nanocomposite Film for Space Application, Tribology Letters, 66 (4): 137.

[3] Tsai D.-C., Chang Z.-C., Kuo B.-H., Chen B.-C., Chen E.-C., Shieu F.-S. 2018. Wide variation in the structure and physical properties of reactively sputtered (TiZrHf)N coatings under different working pressures, Journal of Alloys and Compounds, 750: 350-359.

[4] La J., Song M., Kim H., Lee S., Jung W. 2018. Effect of deposition temperature on microstructure, corrosion behavior and adhesion strength of $\mathrm{Zn}-\mathrm{Mg}$ coatings on mild steel, Journal of Alloys and Compounds, 739: 1097-1103.

[5] Hajihoseini H., Kateb M., Ingvarsson S., Gudmundsson J.T. 2018. Effect of substrate bias on properties of HiPIMS deposited vanadium nitride films, Thin Solid Films, 663: 126-130.

[6] Dubey P., Martinez G., Srivastava S., Chandra R., Ramana C.V. 2017. Effect of bias induced microstructure on the mechanical properties of nanocrystalline zirconium tungsten nitride coatings, Surface and Coatings Technology, 313: 121-128.

[7] Lin J., Sproul W.D., Moore J.J. 2012. Tribological behavior of thick CrN coatings deposited by modulated pulsed power magnetron sputtering, Surface and Coatings Technology, 206 (8): 24742483.

[8] Pakala M., Lin R.Y. 1996. Reactive sputter deposition of chromium nitride coatings, Surface and Coatings Technology, 81 (2): 233-239.

[9] Vite M., Moreno-Ríos M., Hernández E.A.G., Laguna-Camacho J.R. 2011. A study of the abrasive resistance of sputtered CrN coatings deposited on AISI 316 and AISI H13 steel substrates using steel particles, Wear, 271 (9): 1273-1279.

[10] Zhou F., Chen K., Wang M., Xu X., Meng H., Yu M., Dai Z. 2008. Friction and wear properties of CrN coatings sliding against Si3N4 balls in water and air, Wear, 265 (7): 1029-1037.

[11] Ruden A., Restrepo-Parra E., Paladines A .U., Sequeda F. 2013. Corrosion resistance of CrN thin films produced by dc magnetron sputtering, Applied Surface Science, 270: 150-156.

[12] Qi Z., Wu Z., Zhang D., Wei B., Wang J., Wang Z. 2017. Effect of sputtering power on the chemical composition, microstructure and mechanical properties of $\mathrm{CrNx}$ hard coatings deposited by reactive magnetron sputtering, Vacuum, 145: 136-143. 
[13] Hurkmans T., Lewis D.B., Paritong H., Brooks J.S., Münz W.D. 1999. Influence of ion bombardment on structure and properties of unbalanced magnetron grown CrNx coatings, Surface and Coatings Technology, 114 (1): 52-59.

[14] Mayrhofer P.H., Tischler G., Mitterer C. 2001. Microstructure and mechanical/thermal properties of $\mathrm{Cr}-\mathrm{N}$ coatings deposited by reactive unbalanced magnetron sputtering, Surface and Coatings Technology 142-144: 78-84.

[15] Tu J.-N., Duh J.-G., Tsai S.-Y. 2000. Morphology, mechanical properties, and oxidation behavior of reactively sputtered Cr-N films, Surface and Coatings Technology, 133-134: 181-185.

[16] Bertrand G., Savall C., Meunier C. 1997. Properties of reactively RF magnetron-sputtered chromium nitride coatings, Surface and Coatings Technology, 96 (2): 323-329.

[17] Singh S.K., Chattopadhyaya S., Pramanik A., Kumar S. 2018. Wear behavior of chromium nitride coating in dry condition at lower sliding velocity and load, The International Journal of Advanced Manufacturing Technology, 96 (5): 1665-1675.

[18] Thornton J.A. 1977. High Rate Thick Film Growth, Annual Review of Materials Science, 7 (1): 239-260.

[19] Mahieu S., Depla D. 2009. Reactive sputter deposition of TiN layers: modelling the growth by characterization of particle fluxes towards the substrate, Journal of Physics D: Applied Physics, 42 (5): 053002.

[20] Shinmitsu T., Shi J., Hashimoto M. 2002. Effects of substrate-bias on the structure of sputterdeposited Co-Pt film, Surface and Coatings Technology, 151-152: 55-58.

[21] Gilewicz A., Warcholinski B., Murzynski D. 2013. The properties of molybdenum nitride coatings obtained by cathodic arc evaporation, Surface and Coatings Technology, 236: 149-158.

[22] Lee H.Y., Lee D.K., Kang D.H., Lee J.J., Joo J.H. 2005. The effect of r.f. substrate bias on the properties of carbon nitride films produced by an inductively coupled plasma chemical vapor deposition, Surface and Coatings Technology, 193 (1): 152-156.

[23] Grasser S., Daniel R., Mitterer C. 2012. Microstructure modifications of CrN coatings by pulsed bias sputtering, Surface and Coatings Technology, 206 (22): 4666-4671.

[24] Li F., Kang Y., Fu L., Qiao Z., Liu W., Yang J. 2016. Friction and wear behavior of nanoeutectic Fe1.87C0.13 under air and vacuum conditions, Proceedings of the Institution of Mechanical Engineers, Part J: Journal of Engineering Tribology, 230 (4): 481-487.

[25] Wu J.-s., Li J.-f., Zhang L., Qian Z.-Y. 2017. Effects of environment on dry sliding wear behavior of silver-copper based composites containing tungsten disulfide, Transactions of Nonferrous Metals Society of China, 27 (10): 2202-2213.

[26] Amirat M., Sawalem M., Zaïdi H. 2013. Influence of the Gas Environment on the Transfered Film of the Tribologic Brass (CuZn)/XC48 Steel COUPLE, Applied Mechanics and Materials, 367: 32-39. 